\title{
LEVIN GOLDSCHMIDT
}

\author{
Peter Walter Ashton ${ }^{1}$
}

Levin Goldschmidt nasceu em em Heidelberg publicou: Crítica do 17 maio de 1828, na cidade de Dan- Projeto de Código Comercial para zig, Alemanha, atualmente Polônia. os Estados Prussianos e ainda PareFaleceu em Bad Wilhelmshöhe, hoje cer do Projeto de Código Comercial KasseL, Alemanha, em 16 de julho de Alemão. Publicações elogiadas e que 1897. De 1847 a 1851 , Goldschmidt estudou Ciências Jurídicas e Sociais nas Universidades de Berlim, Bonn e Heidelberg, obtendo o título acadêmico de doutor em Direito em 1851, pela Universidade de Halle. Advogou durante alguns anos perante os tribunais da sua cidade natal, Danzig. Obteve, em 1855, o título de Livre Docente pela Universidade de Heidelberg, onde passou a ser professor adjunto em 1860. Enquanto professor passaram a caracterizá-lo como um jurista perspicaz, crítico e ponderado. Nesta época (1858), fundou a Revista Jurídica Para Todo Direito Comercial: Zeitschrift Für das Gesamte Handelsrecht. Pouco depois, em 1862, ainda em Heidelberg, publica: Excorço de Uma Enciclopédia das Ciências Jurídicas - Encyclopädie der Rechtswissenschaft im Grundriss. A partir de 1862, passa a dedicar-se a escrever a sua obra magna: História

1 Professor titular aposentado nas Faculdades de Direito da Universidade Federal do Rio Grande do Sul (UFRGS) e da Pontifícia Universidade Católica do Rio Grande do Sul (PUCRS). Mestre e doutor em Direito. Livre-docente em Direito Comercial. Advogado militante e consultor jurídico. 
Universal do Direito Comercial, que lhe rendeu o reconhecimento internacional como o mestre da história do direito comercial.

Em 1866, Goldschmidt foi promovido a catedrático da Faculdade de Direito de Heidelberg. A seguir, foi distinguido com a posição de Conselheiro de Justiça junto ao Tribunal Federal Comercial de Leipzio. Pouco depois, passou a atuar no Superior Tribunal Comercial do Império. Em 1875, convidado, passou a lecionar como catedrático na Universidade de Berlim. Em Berlim foi distinguido com o título e a posição de Conselheiro Secreto de Justiça. Também foi Deputado Federal do Reichstag Alemão, representando a cidade de Leipzig.

Como professor, Goldschmidt também se interessou pela montagem e currículo dos estudos das Ciências Jurídicas e Sociais - dos Cursos de Direito - publicando: O Estudo tri-anual das Ciências Jurídicas e do Estado. Analisou o conteúdo dos cursos jurídicos bem como as provas e os exames de estado de aprovação dos ditos cursos.

Goldschmidt venerava o historiador Theodor Mommsem, nascido em 1817, professor de Direito e História Romanos em Zurich e Berlim que, com o seu livro A História de Roma, foi distinguido com o Prêmio Nobel de Literatura em 1902.

Em decorrência dessa admiração por Mommsem e seu estilo de pesquisa, a obra de Goldschimdt também é uma admirável pesquisa das fontes do Direito Comercial abrangendo um arco de riquíssimo material de fontes de mais de dois mil anos.

Na sua obra magna História Universal do Direito Comercial, inicia Goldschmidt com a análise do conceito e dos ramos do Direito Comercial.

Traça as linhas básicas e os princípios de um Direito Comercial Universal. Aponta as origens históricas e as características do Direito Comercial (DC) como um direito especial (Sonderbildung). Ressalta o espírito reformista do DC frente ao Direito Civil generalista. Registra a necessidade de colecionar as fontes do DC e de um exame criterioso da literatura jurídica de cunho comercialista. Estabelece vinculações do DC com a história cultural dos povos e com as economias nacionais.

No segundo capítulo do seu livro mostra um panorama histórico do desenvolvimento do DC. A seguir, no capítulo três, ao analisar problemas econômicos e jurídicos básicos do $\mathrm{DC}$, foca a situação do DC nos tempos históricos pré-escrita e pós-escrita, analisando o escambo e o comércio de compra e venda, a moeda, os ambulantes, o comércio estabelecido, o comércio em nome próprio e o comissionado, o comerciante estrangeiro, o papel do tradutor, dos corretores o comércio a varejo e por atacado.

Passa a analisar preços, mercados e feiras. $\mathrm{O}$ transporte dos bens por ter- 
ra e mar. A formação das caravanas, a construção de estradas e a formação de cidades.

Analisa os tipos de embarcações, o comércio marítimo, a pirataria e os almirantados. Ressalta a importância superior do comércio marítimo para a formação do DC. Trata das feitorias comerciais e da fundação de colônias.

Destaca a importância do crédito, dos juros do capital e os excessos das cobranças de juros bem como o anatocismo. Ressalta a importância do Direito das Obrigações, do comércio bancário da expansão, da exportação de bens.

Mostra Goldschmidt a organização capitalista da sociedade. Trata da importância histórica da escravidão para o comércio na antiguidade e as influências do feudalismo. Registra o pleno desenvolvimento das associações com o desaparecimento da escravidão e do feudalismo. Passa a analisar o surgimento dos diversos negócios comerciais diferenciados e a tendência de simplificação e padronização dos negócios. Critica a diminuição (Verengung) das atividades comerciais privadas pela ingerência do poder estatal.

Apresenta as origens históricas dos institutos jurídicos comerciais. Explica a metodologia de análise e pesquisa histórico-genética em contraponto à metodologia de pesquisa por isolamento dogmático.

Perfila os principais povos que com a sua cultura promoveram o co- mércio mundial internacional. Destaca fenícios, gregos e romanos. Destaca, analisa e diferencia o Direito Comercial Universal do nacional.

No capítulo 4, inicia a análise do DC da antiguidade. Dá um panorama: dos países do Mar Mediterrâneo, Egito, Babilônia, Assíria, Fenícia, Grécia, especialmente Ática. Rhodos e o pseudo Direito Marítimo da Ilha de Rhodos. Apresenta e analisa as teorias dos filósofos da antiguidade sobre comércio e comerciantes.

Dedica atenção especial na sua análise e estudo a Roma. Assim explica o que, para Roma, significava comércio e trabalho. Caracteriza a situação econômica de Roma ao fim da república e na época imperial.

Analisa a economia monetária romana e o tráfego creditício da época. Mostra a centralização do comércio e dos institutos a ele vinculados no império romano. O comércio romano atacadista capitalista. Assinala a paucidade em Roma de normas especiais de Direito Comercial confrontada com a elasticidade e pujança do jus civile comum. Destaca elementos e características do jus civile comum quando empregado para regular o comércio e o tráfego comercial. O direito da URBS, o direito vulgar e as usances - usos e costumes comerciais da época. Confronta o direito da cidade de Roma ius civile com o ius gentium. Da época do império alto. 
No capítulo 5, Goldschmidt analisa a situação do Direito Comercial na Idade Média. Perfila potências mundiais da época e a posição da Igreja Católica: O Império Bizantino. Os árabes. A monarquia dos francos. Tribos germânicas e povos romanizados. Cidades e associações profissionais. Ordens religiosas. Mosteiros. A posição dos judeus. A proteção real dos comerciantes do santo império alemão. Os direitos das feiras, dos comerciantes medievais. As corporações. A liga Hanseática. Medidas e Pesos. Os perigos e obstáculos do comércio por terra e por mar/fluvial. A pirataria, assaltos, vingança. O Contrato de Prestação de Serviços de homens livres. Feitorias. Milícias de proteção. As alfândegas, Direitos de Hospedagem. Sistema de Represálias. Trancamento monopolístico. Uso do Direito Romano e do Direito Germânico. As certidões. A polícia de trânsito dos francos. Novos usos e costumes. Jurados e juízes das cidades e das feiras, idem ao policiamento. A paz nos mercados e nas feiras. A assinatura mercantil civil nos contratos. A internacionalização dos usos e costumes comerciais. Influências mercantis no Direito Processual. A visão jurídica germânica em luta parcialmente vitoriosa contra o Direito Romano. A legislação e a prática da Igreja Católica Romana. A teoria católica dos juros extorsivos. A tutela religiosa dos negócios mercantis e em geral.
A seguir, Goldschmidt passa a estudar os países do Mediterrâneo, especialmente a Itália. Razões do precoce desenvolvimento mercantil da Itália. Veneza, Amalfi, Pisa, Gênova, Lucca, Milano, Bolonha, Florença, Roma etc. O Direito Estatutário. Os usos e costumes. A prática dos tabeliães. Certidões e certificações. Contratos de comércio marítimo e terrestre. As constituições das cidades. As associações dos cambiadores de moedas e dos banqueiros. A Lombardi. As constituições e os estatutos das corporações, especialmente os estatutos dos comerciantes. Os tribunais consulares. A "questio commercium" ou "Handelsache". O processo respectivo. Os consulatus maris e outros direitos marítimos especiais. Os juizados de medidas e pesos. O tráfego internacional e os tratados entre estados soberanos. Os cônsules itinerantes e os permanentes. Os comerciantes italianos no exterior. Associações de comerciantes de diversas cidades ou de nações. Os comerciantes italianos na França.

\section{A PENÍNSULA IBÉRICA. FRANÇA. AS FEIRAS FRANCESAS}

Capítulo VI. Os resultados da formação de normas jurídicas derivadas dos Direito Romano na Idade Média. O Direito Pessoal: o comerciante, a 
matrícula, o registro comercial, as filiais, as marcas de comércio. A firma. Menores. Mulheres casadas ou comerciantes. Livros. Contabilidade. Os direitos dos corretores, aprendizes e estagiários. Os empreendimentos comerciais (societários). Tipos diversos. Origens diversas. A Commenda. A sua história na Antiguidade, no Direito Bizantino. Sua vinculação com o empréstimo marítimo. A Commenda com participação de capital unilateral e bilateral (societas maris - societas terrae). A Commenda como negócio de crédito geral (com forma societária). A gerência do negócio. Pluralidade de commendas. Transposição da commenda ao comércio terrestre, especialmente aos negócios bancários. Vinculação da commenda ao depositum irregulare. Separação paulatina dos bens da sociedade dos bens especiais dos participantes. Obrigação de registro. A firma da sociedade. Accomandita e a participatio. A colonna.

A sociedade aberta e coletiva ( $A$ Compagnia). A firma dessa sociedade. A sua representação. $\mathrm{O}$ seu registro. $\mathrm{O}$ registro geral das sociedades. As relações internas. Os bens societários separados e especiais (corpo della societas). A obrigação de prestar contas. $\mathrm{O}$ processo de liquidação. $\mathrm{O}$ fechamento de negócios de parte de sócios individuais, sob a forma da sociedade, baseia-se originalmente sobre a procuração. A outorga recíproca de poderes tem origem nos usos e costumes: é a fórmula presuntiva multilateral da prepositio institória. Paulatina formação da responsabilidade ilimitada dos sócios. Vinculação com a estipulação usual de responsabilidade solidária. Vinculação ao sistema de represálias. Relação nas origens à associação familiar germânica. Especialmente a restrição dispositiva de bens. A copropriedade.

As sociedades de capital de ações. Sua origem no empréstimo a juros vinculado ainda ao arrendamento (compera). Os empréstimos públicos: monte, maona. A associação de capital dos credores do Estado (societates comperarum, monti, maonae), especialmente em Gênova. As maonae das ilhas de Chios Phokaea e Chipre. O Banco de São Jorge.

O Direito das Coisas. O sistema de reivindicações. A cláusula constituti. A traditio simbólica ou ficta. $\mathrm{O}$ Direito de perseguir o bem. O Direito do Penhor. O direito de retenção. Papéis de transporte e de depósito/armazenamento.

O Direito Contratual. Generalidades. A equitas mercatoria e os usos e costumes comerciais. $\mathrm{O}$ tráfego creditício, especialmente o internacional. $\mathrm{O}$ contrato sem forma. $\mathrm{O}$ contrato abstrato e a cautio indiscreta. O processo de execução. As renúncias usuais ao direito de questionar o contrato. A cláusula privilegia fori. O pagamento em quaisquer localidades. Vantagens processuais. Direito à cláusula solidá- 
ria e obrigações decorrentes da cláusula solidária. Renúncia aos beneficia excussionis e divisiones. Representação e mandato. Confirmação da prestação em relação a terceiros e por meio de terceiros. Pena convencional. Juros moratórios. Indenização. Prova do direito aos juros moratórios. A obrigação de contratar. A Lex Anastasiana. Moeda, moeda mundia, moeda da conta. A cláusula "de acordo com o valor e a cotação". Preocupação com o curso da moeda correta. Operações de crédito e de pagamento. Bolsas. Custo das mercadorias e do dinheiro.

Os principais negócios comerciais da época: compra e venda, câmbio, pesos e medidas. Bens do comerciante. Ação redibitória. Restrições a reclamações. $\mathrm{O}$ empréstimo a juros. $\mathrm{O}$ negócio bancário. O negócio do depósito e as cédulas defitais (fedi: cédula bancária primitiva). A concordância de pagar do banqueiro caracterizada por uma certidão de crédito no livro do banco. Equivalência desta certidão de crédito a um pagamento à vista. Os negócios de capital de giro. $\mathrm{O}$ cheque giro e o cheque de pagamento. Abertura de crédito. A prestação de contas. Os negócios de conta corrente. A fiança do crédito. Os negócios de remessa e de cobrança. As negociações de empréstimo. $\mathrm{O}$ desconto. $\mathrm{O}$ banqueiro particular e os bancos públicos. $\mathrm{O}$ negócio comissionado e o negócio de expedição. $\mathrm{O}$ negócio de fretamento de cabotagem e a certidão de carrega- mento. A Carta de fretamento. Comunicação. Os negócios do armazém de depósito e o certificado de depósito.

Capítulo VII - O Direito Marítimo. O empreendimento comercial de pequena envergadura e a sua regulamentação jurídica. Situação econômica que se aproxima da situação econômica existente ao tempo do império romano. Consulate del Mar e Direito romano. $\mathrm{O}$ navio. $\mathrm{O}$ armador. Sua responsabilidade ampliada. Responsabilidade limitada. A mercadoria embarcada. $\mathrm{O}$ armador correspondente. $\mathrm{O}$ contrato de fretamento. A lista de bens embarcados e o conhecimento de transporte. O contrato de transporte de passageiros. Avaria. Colisão de navios. Salvamento. O Empréstimo marítimo. Negócios creditícios em geral em relação à chegada segura. $\mathrm{O}$ empréstimo considerando perigos em terra. A compra a crédito e a compra de bens a serem fornecidos considerando perigos marítimos. O surgimento do contrato (em alemão, Bodmerei, em francês, Contract à la Grosse e em inglês Bottomry). A letra de câmbio marítimo. $\mathrm{O}$ processo no Direito Marítimo.

Capítulo VIII - O Seguro. Características gerais. $\mathrm{O}$ seguro recíproco. A ideia do seguro com prêmio moderno surgiu na Itália ao redor dos séculos XIII e XIV. Originou-se do contrato de empréstimo marítimo e por muito tempo sua formatação seguiu as características deste último. Não se originou da aposta (sponsio). 
A contratação do seguro considerando os perigos e a repartição do risco passou a ser um negócio profissional. $\mathrm{O}$ interesse assegurado e o seguro aposta. Sua relação com o anatocismo. A apólice. Direito do seguro marítimo a partir do fim do século XIV. Obrigação de comunicação. Estorno. Presunção, vale dizer, ficção do momento do acontecimento do sinistro. Abandono. O processo. A legislação.

Capítulo IX. O Direito das Certidões e Certificações. A certificação dos negócios jurídicos. Os lançamentos contábeis. Certidões entregues ao destinatário como material de prova. Os títulos de crédito. Origem e natureza jurídica. Títulos à ordem, nominativos e ao portador. A cláusula à ordem ativa como elemento típico da certidão dos negócios na Idade Média. Seu significado jurídico. A indicação do favorecido da cláusula à ordem por intermédio de uma certidão procuratória, após conhecido como Endossemant (endosso), também conhecido como girata aposto no título. Os títulos nominativos. Os títulos ao portador. As cartas de crédito gerais a favor de pessoas desconhecidas. A cláusula à ordem passiva: per me vel per meum nuncium (missum) e similares. Os subprocuradores (Surrogate) dos mesmos. O negócio à distância, especialmente o negócio cambial.

Capítulo X. A letra de câmbio. Conceito técnico. O negócio cambial oral. O negócio cambial escrito é $a b$ initio um negócio creditício de caráter geral utilizado para remessa de dinheiro para uma outra praça. Origem na Antiguidade e na Idade Média. Origem no comércio marítimo no exterior. Negócio que se aproxima do empréstimo marítimo como negócio de remessa. A cláusula latina "salvum interra". Passagem do instituto jurídico para os negócios internos ou domésticos. A forma mais antiga da certidão de câmbio ou da letra de câmbio é a letra de câmbio própria domiciliada. Há provas da sua existência desde a metade do século XII. Sua forma típica. A cláusula cambial especialmente as relações múltiplas de moedas (valuta) diferenciadas. Obrigação de indenizar, automática, do emitente da letra de câmbio em certas condições como obrigação de regresso. A letra de câmbio na sua origem era uma remessa de dinheiro comum, inicialmente sem obrigação de regresso do emitente da letra. Não originária de registros contábeis. Meramente execução da letra de câmbio própria que é necessariamente a sua base, bem como por inserção e preenchimento da cláusula à ordem ativa e passiva. Daí a expressão "tracta et remissa". As quatro pessoas envolvidas na letra de câmbio medieval. Prova da existência da letra de câmbio desde meados do século XIII. A letra de câmbio original transforma-se na Carta de Câmbio autônoma. 
Isso assim ocorre porque a letra de câmbio passa a incorporar, necessariamente, os elementos intrínsecos da carta de câmbio e, por isso, não necessita como base um câmbio próprio especial. $\mathrm{O}$ entendimento implícito da promessa de regresso na letra de câmbio de parte do sacador. Quem pode usar da ação de regresso. $\mathrm{O}$ desenvolvimento e a formação da letra de câmbio para um título à ordem. $\mathrm{O}$ endosso. $\mathrm{O}$ aceite. $\mathrm{O}$ aval. As duplicatas. As intervenções cambiais. $\mathrm{O}$ protesto. $\mathrm{O}$ regresso. A prescrição e a data de vencimento. O comércio das letras de câmbio e as cotações das letras de câmbio. O processo de cobrança. As leis cambiárias. A literatu- ra especializada. A posição da Igreja face aos negócios cambiários.

Esse vasto elenco de matéria de Direito Comercial pesquisado, ordenado e verificado como foi por Goldschmidt, em 1891, vê-se hoje reproduzido, mais de 120 anos depois, em todos os manuais brasileiros de direito comercial. Pode ser afirmado, com certeza e tranquilidade, que os atuais autores e professores de Direito Comercial seguem, quase ao pé da letra, a forma e o conteúdo da matéria de Direito Comercial tal como foi apresentada no fim do século XIX por Goldschmidt, que assim tornou-se o guia seguro de todos os professores de Direito Comercial que o seguiram. 